\title{
Ecological State of Water and Soil of Natural-Anthropogenic Landscapes in the Oil-Producing Regions
}

\author{
Urazmetov I.A. \\ Smirnova E.V.
}

Kazan Federal University, Russia, 420008, Kazan, Kremlevskaya 18

Doi:10.5901/mjss.2014.v5n18p367

\begin{abstract}
The article studies the geological state of natural-and-anthropogenic landscape complexes in oil extraction regions of the Republic of Tatarstan and describes landscape characteristics on the basis of current ecological condition of natural surface and underground waters and soil. The degree of natural functioning of geological systems transformed due to oil extraction is pointed out on the example of internal landscape forming factors.
\end{abstract}

Keywords: geological state, landscape components, soil, natural-and-anthropogenic landscapes, oil pollution, transformation of environmental properties.

\section{Introduction}

Contamination of areas with oil and oil products, substances of the most dangerous and widespread pollutants of the environment $[1,6,9,11]$, is one of the important geo-environmental problems. This fully applies to the Republic of Tatarstan, where there are numerous oil and petrochemical industries, and where intensive extraction and refining occurs. From the bowels of the earth has already been withdrawn about 2 billion 900 million tons of oil. Oil production has reached 3493 ha (52\% of the total area of the country), and the most common in the oil fields of soils is black earth. According to a 55-year period in the Republic mining 1 ton of oil is accompanied by destruction or contamination of 1-1.3 $\mathrm{m}^{3}$ of land.

In the geographical envelope, soil and natural waters are so-called bio-inert subsystems of the landscape. Surface waters are part of the hydrosphere and soils develop as a result of interactions between the atmosphere, hydrosphere, lithosphere and biosphere, as well as being one of the main landscape-forming factors. Therefore the study of the transformation properties of the soil and water pollution as a result of pollution by oil and oil products, at the present stage of development and transformation of geosystems is one of the urgent tasks $[4,8,10]$

As a result of the degradation of natural and man-made landscapes associated with the extraction and processing of oil, soil, and their constituents lose fertility, their water, physical, chemical and microbiological properties deteriorate, reducing the quality and productivity, and as a consequence, the output of agricultural activity. In addition, the risks of the transformation of the adjacent landscaped environments, such as vegetation, groundwater and surface water, surface layers of the atmosphere appear $[2,3,5,7]$.

The aim of this work was to study the current ecological state of natural components that make up the landscapes in oil-producing areas of the Republic of Tatarstan and the identification of factors that influence the changes in the properties and functioning of the transformed geosystems.

The objects of study are the surface and ground waters and soil of natural and man-made landscapes, which in accordance with the landscape division of the territory of the Republic of Tatarstan are part Cheremshan-Ikskogo and Nizhnezainskogo sublime landscape areas.

Assessment of impact on geo-ecosystems and action of pollutants such as oil and oil related products in the landscapes is related first of all to the problems of migration and retention in landscape systems. Migratory movements characteristic of oil-component systems are the basis of the forecast of the landscape effects of pollution, the speed of self-purification and recovery of damaged landscapes.

In numerous studies conducted in the oil-producing regions of Russia, it was shown that oil and oil products actively migrate in any of the natural landscape areas and processes related to their migration and metabolism are complex, time-consuming, and depend, in general, on the physical and geographical conditions of the area (Breus et al, 


\section{Results and Discussion}

Current ecological state of natural and ground waters. On the territory of studied areas numerous underground springs are located. From the results of chemical analysis of water samples of groundwater sources in Table 1, we can draw conclusions about stable exceed in them of total hardness. So, figure of the total hardness of groundwater ranged from 7.2 to $15.6 \mathrm{mg}-\mathrm{Eq} / \mathrm{L}$ and an average was $8.5 \mathrm{mg}-\mathrm{Eq} / \mathrm{I}$. In this regard, water underground sources can be considered as moderately hard and tough. Within other components significant exceeds of the maximum permissible concentrations have not been identified, particularly in terms of residual oil. The average rate of excess of maximum allowable concentrations of pollutants of ground waters was less than 1, and their status can be assessed as relatively satisfactory, based on the main parameters studied.

Table 1. Results of chemical analysis of samples from ground water sources

\begin{tabular}{|l|c|c|c|}
\hline Defined parameters & Measurement unit & MPC & Ground waters (medium numbers) \\
\hline Total hardness & $\mathrm{mg}^{*} e q . /$ & 7 & 8,5 \\
\hline General mineralization & $\mathrm{mg} / \mathrm{l}$ & 1000 & 720 \\
\hline $\mathrm{Cl}^{-}$ & $\mathrm{mg} / \mathrm{l}$ & 350 & 57 \\
\hline $\mathrm{SO}_{4}{ }^{-2}$ & $\mathrm{mg} / \mathrm{l}$ & 500 & 83 \\
\hline $\mathrm{pH}$ & $\mathrm{unit}$ & $6-9$ & 7,8 \\
\hline Petrochemicals & $\mathrm{mg} / \mathrm{l}$ & 0,1 & 0,0120 \\
\hline
\end{tabular}

Chemical analysis of samples of surface water bodies within the landscape profile are given in Table 2. The data signifies the exceed in the surface waters of the total hardness parameter and calcium content. On the other components no exceeds were found. The measure of the total hardness averaged $10.02 \mathrm{mEq} / \mathrm{I}$. Water streams are considered moderately hard and hard and can be attributed to the type - fresh bicarbonate-magnesium-calcium, salinity $763.2 \mathrm{mg} / \mathrm{I}$.

Since, some of the indicators of oil pollution of water bodies are the content in surface water of chloride, sulphate and residual oil, such studies have been conducted and reported in Table 2. Based on the data, it is possible to conclude the absence in the water samples of chloride ions, sulfate ions, and petroleum products, which indicates absence of flow into the surface water of income to surface water of such contaminants as oil and petroleum products.

Table 2. Results of chemical analysis of surface waters

\begin{tabular}{|l|c|c|c|}
\hline Defined parameters & Measurement unit & MPC & Surface water (medium numbers) \\
\hline Total hardness & $\mathrm{mg}^{*} \mathrm{eq} . / \mathrm{l}$ & 7 & 10,02 \\
\hline General mineralization & $\mathrm{mg} / \mathrm{l}$ & 1000 & 763,2 \\
\hline $\mathrm{Cl}$ & $\mathrm{mg} / \mathrm{l}$ & 300 & 65,8 \\
\hline $\mathrm{SO}_{4}{ }^{-}$ & $\mathrm{mg} / \mathrm{l}$ & 100 & 78,6 \\
\hline $\mathrm{pH}$ & $\mathrm{unit}$ & $6,5-8,5$ & 7,2 \\
\hline $\mathrm{Ca}^{2+}$ & $\mathrm{mg} / \mathrm{l}$ & 180 & 112,0 \\
\hline $\mathrm{Mg}^{2}$ & $\mathrm{mg} / \mathrm{l}$ & 40 & 43,9 \\
\hline Oil products & $\mathrm{mg} / \mathrm{l}$ & 0,05 & 0,0123 \\
\hline
\end{tabular}

Soil conditions and the assessment of the current ecological state of soils. Based on natural and agricultural zoning studied territory of laying landscape profile belongs to the Preduralskoy province steppe zone, district: sublimely ridged loam leached chernozem and meadow-alkaline-black earth. Based on agro-soil zoning the territory relates to the Northeastern and western regions of Zakamye.

In areas affected by oil, the analysis of the distribution of the land fund categories and lands, we can note a significant predominance of agricultural land, due to the wide spread in the area of highly fertile soil, which are black earth and grey forest. Thus, based on the soil structure, Almetyevsk district refers to the area with a high proportion of black earth $(70-90 \%)$. And the area is dominated by the most valuable typical black earth. Novosheshminsky area refers to the area with the average proportion of black earth (50-70\%), is dominated by leached black earth and dark-grey forest soils. Zainsky area refers to areas with a lower share of black soil (20-50\%), where the soil cover is dominated by gray forest (27-44\%), and brown-gray forest (to $21 \%$ ), as well as sod-calcareous soils (up to $8 \%$ ).

Based on particle size contents, which widely determines the level of soil resistance towards human impacts, and 
first of all determines the type of migration of petroleum hydrocarbons in the soil profile, within soil types clay and heavy clay ones dominate, they account for over $76 \%$ of the land farms.

Erosion processes caused primarily by agricultural use of soil (land disturbance, high plowed, breach technology of agriculture), are one of the strongest negative factors affecting soil fertility and resistance to anthropogenic stress. In terms of area of eroded soils Almetyevsk district is classifies as "restricted-favorable", there, the share of soils prone to erosion make up $10-25 \%$ of all arable land, and Novosheshminsky and Zainsky districts are classified as "unfavorable", up to $80 \%$ of agricultural lands are considered eroded.

Physics-chemical properties of soil largely determine soil fertility, resistance to anthropogenic loads, the use of topsoil for reclamation activities on marginal lands. According to these properties, most of soils in the study can be attributed to highly fertile and with a high degree of resistance to anthropogenic stress. Since they are characterized by considerable humus horizon $(40-70 \mathrm{~cm})$, humus content - 4,8-8,3\%, mostly slightly acidic and near neutral, in some cases, slightly alkaline reaction medium. According to its water-physical properties, they are weakly previous and have high-plasticity properties.

Another important factor that allows to assess the sustainability of the landscape to anthropogenic stresses is the location of soils types of relief and the presence in the soil profile of geochemical barriers. In this regard, the most stable are eluvial soil (upland) elementary landscapes possessing sorption, neutral and partly calcareous geochemical barriers. These soils are all subtypes of black earth, as well as turf-carbonate, gray forest and partly meadow black earth. Place a sink for pollutants are geochemically and subaqueous superaqual elementary landscapes, which are mainly the sorption and carbonate geochemical barriers. These locations are confined part of the meadow-black earth, meadow marsh calcareous alluvial sod acidic and calcareous soils. As shown above, the soil cover of the study territory is dominated by black earth leached, typical black soil of the residual carbonate, gray forest and dark-gray forest soils related to the filler surface water dividers, i.e. to eluvial landscapes.

In order to assess the general condition of the soil cover natural and man-made landscapes of oil-producing areas, soil environment has been studied. Soil samples were taken along the trajectory of landscape structure. Soil sampling performed with the vertical structure, the heterogeneity of soil, topography and type of land as well as the placement of oil facilities in the locality. Results of analysis of soil samples presented in Table 3 show that the content of almost all studied components does not exceed the maximum permissible concentration in the soil. Thus, the oil content in the samples of soil samples varies from 15.3 to $192.0 \mathrm{mg} / \mathrm{kg}$, with an average of $103.7 \mathrm{mg} / \mathrm{kg}$, and the maximum permissible concentrations were not observed. Therefore, the level of soil contamination in the study area on the oil content can be attributed to the allowable.

Monitoring of soil contamination with toxic substances of industrial origin, which include heavy metals is also a key part of monitoring the state of the environment in the areas of mining and oil refining.

The main sources of heavy metals in the soil of the landscape is their loss with precipitation, the transfer of surface water, as well as to the soil and groundwater runoff. Thus the concentration of heavy metals in soils of studied landscapes does exceed the maximum allowable concentrations for clay, loam and sandy loam soil types with $\mathrm{pH}>5.5$. Approximate values of the background of gross forms of metals for black earth for zinc is $68 \mathrm{mg} / \mathrm{kg}$, cadmium - $0.24 \mathrm{mg}$ / kg, lead - $20 \mathrm{mg} / \mathrm{kg}$, mercury - $0.2 \mathrm{mg} / \mathrm{kg}$, copper - $25 \mathrm{mg} / \mathrm{kg}$, nickel - $45 \mathrm{mg} / \mathrm{kg}$, arsenic - $5.6 \mathrm{mg} / \mathrm{kg}$, respectively.

The content of heavy metals in the soil samples of studied landscapes in most cases is well below background values (Table 3).

Table 3. Results of soil samples chemical analysis

\begin{tabular}{|l|c|c|c|c|}
\hline Parameters & Measurement unit & MPC & The background concentration of pollutants in the soil & Soils (medium numbers) \\
\hline $\mathrm{pH}$ & unit. & Not norm. & - & 7,5 \\
\hline $\mathrm{Cl}$ & $\mathrm{Mg} / \mathrm{kg}$ & 360,0 & - & 26,5 \\
\hline $\mathrm{SO}_{4}{ }^{2-}$ & $\mathrm{Mg} / \mathrm{kg}$ & 160,0 & - & 109,8 \\
\hline Petrochemicals & $\mathrm{Mg} / \mathrm{kg}$ & 1500 & - & 103,7 \\
\hline Lead & $\mathrm{Mg} / \mathrm{kg}$ & 130,0 & 20 & 0,0152 \\
\hline Cadmium & $\mathrm{Mg} / \mathrm{kg}$ & 2,0 & 0,24 & 0,0010 \\
\hline Arsenic & $\mathrm{Mg} / \mathrm{kg}$ & 10,0 & 5,6 & 0,0223 \\
\hline Copper & $\mathrm{Mg} / \mathrm{kg}$ & 132,0 & 25 & 0,8271 \\
\hline Zink & $\mathrm{Mg} / \mathrm{kg}$ & 220,0 & 68 & 0,2212 \\
\hline Nickel & $\mathrm{Mg} / \mathrm{kg}$ & 80,0 & 45 & 0,1798 \\
\hline Mercury & $\mathrm{Mg} / \mathrm{kg}$ & 2,1 & 0,2 & Not found \\
\hline Chrome & $\mathrm{Mg} / \mathrm{kg}$ & 0,05 & - & 0,0124 \\
\hline
\end{tabular}


Within the present study, the level of chemical contamination of soil in areas of oil production has been defined. To characterize the level of pollution of the landscape profile the total pollution index Zc is used, which is defined as the ratio of fixed content element to its background value. As background level concentrations of chemicals regional rates have been used of soil in relation of content within them of $\mathrm{Cu}, \mathrm{Zn}, \mathrm{Pb}, \mathrm{Ni}$. The average concentration of heavy metals in soil of the studied area is presented in Table 4.

Table 4. Average concentration of heavy metal in oil-producing regions of republic of Tatarstan

\begin{tabular}{|l|c|c|c|c|c|}
\hline \multirow{2}{*}{ Region } & \multicolumn{5}{|c|}{ Element concentration, mg/kg soil } \\
\cline { 2 - 6 } & $\mathrm{Cu}$ & $\mathrm{Zn}$ & $\mathrm{Pb}$ & $\mathrm{Cr}$ & $\mathrm{Ni}$ \\
\hline Almetyevsky & 44 & 63 & 16 & 230 & 58 \\
\hline Novosheshminsky & 42 & 66 & 16 & 190 & 59 \\
\hline
\end{tabular}

Summary indicator of chemical pollution (Zc) characterizes the degree of chemical contamination of soil and ground of the studied area with harmful substances of different classes of risk. Intervals of the indicator of chemical pollution and the corresponding categories of soil contamination are shown in Table 5.

Table 5. Categories of soil contamination, depending on the size of the total index of chemical pollution

\begin{tabular}{|l|c|l|}
\hline $\begin{array}{l}\text { Categories of soil } \\
\text { contamination }\end{array}$ & $\begin{array}{c}\text { Total index of } \\
\text { pollution Zc }\end{array}$ & Characteristics of soil pollution \\
\hline Admissible & $<16$ & Chemical content of the soil exceed the background content, but no more than MPC \\
\hline Moderately dangerous & $16-32$ & $\begin{array}{l}\text { Chemical content in the soil exceeds its MPC along with limited water migration and air } \\
\text { migration danger index, but it is less than admissible level translocation indicator }\end{array}$ \\
\hline Dangerous & $32-128$ & Chemical content in soil exceed its MPC along with limited translocation hazard indicator \\
\hline Extremely dangerous & $>128$ & Chemical content in soil exceeds MPC in soil based on all hazard indicators \\
\hline
\end{tabular}

The results of calculations of the total soil pollution index $(\mathrm{ZC})$, which were based on analytical data of heavy metals in selected soil samples were $\leq 16(\mathrm{ZC} \leq 16)$. This indicates the level of soil contamination of the territory as admissible.

\section{Conclusion}

Therefore, the results of the study give evidence of the geo-environmental conditions and specific needs of natural and man-made landscapes in areas of oil production. Absence of a substantial transformation of environmental condition and properties of domestic natural components within the system landscape, in the presence of anthropogenic impact can be noted.

Thus, concentration of pollutants in the soil, surface and ground waters of the studied landscape does not exceed the maximum permissible value, which characterizes the natural stable functioning of natural-territorial areas, which have been converted during economic activity.

\section{References}

Breus I.P., Smirnova-Efstifeva E.V. et al. Transportation of liquid hydrocarbons in leached chernozem [Text] // Eurasian Soil Science. 2005. - №6. - P. 1084 - 1096.

Caravaca F., Roldan A. Assessing changes in physical and biological properties in a soil contaminated by iol sludges under semiarid Mediterranean conditions // Geoderma. 2003. Vol. 117. Iss. 1-2.

Ibatullina I.Z., Yakovlev A.S. et al. Specific features of oil biodegradation in meadow-chestnut soil of the Stavropol Region (model experiment) // Eurasian Soil Science. - 2012. - №3. - P. 329-336.

Lethbridge G., Wenham M.F. (Shell Global Solutions) Addressing soil contamination in IPPC Site Baseline and Site Closure Reports // The Soil and Croundwater Technology Association. http://www.sagta.org.uk.

Li J., Zhang J., Lu Y. et al. Determination of total petroleum hydrocarbons (TPH) in agricultural soils near a petrochemical complex in Guangzhou, China // Environ. monitoring and assessment. 2012. Vol. 184, №1.

Mcgill W.B. Soil restoration folio wing oil spiels - a review // J.of can. Petroleum Technology. Ahril-June 1977. P. 60-67.

Mikkonen A., Hakala K.P., Lappi K. et al. Changes in hydrocarbon groups, soil ecotoxicity and microbiology along horizontal and vertical contamination gradients in an old landfarming field for oil refinery waste // Environ. Pollution. 2012. Vol. 162.

Pikovskii YU.I., Gennadiev A.N. et al. The problem of diagnostics and standardization of the levels of soil pollution by oil and oil products 
// Eurasian Soil Science. - 2003. - №9. - P. 1010-1017.

Smirnova E.V., Breus I.P. Transportation of liquid hydrocarbons in leached chernozem. Germany: LAP LAMBERT Acalemic Publishing, 2013. - $73 p$.

Udo E.J., Payemi A.A. The effect of oil pollution of soil on germination, growth and nutrient uptake of com // J.Environ. Quality, $1975 . V 4$. P. 537-540.

Yakovleva E.V., Beznosikov V.A. et al. Bioaccumulation of polycyclic aromatic hydrocarbons in the soil-plant systems of the NorthernTaiga biocenoses // Eurasian Soil Science. - 2012. - №3. - P.309-320. 
